\title{
Bacterial volatile ammonia regulates the consumption sequence of D-pinitol and D-glucose in a fungus associated with an invasive bark beetle
}

\author{
Fangyuan Zhou ${ }^{1,2,6}$, Letian $\mathrm{Xu}^{1,3,6}$, Shanshan Wang ${ }^{1,4,6}$, Bo Wang ${ }^{1,5}$, Qiaozhe Lou ${ }^{1}$, Min $\mathrm{Lu}^{1}$ \\ and Jianghua Sun ${ }^{1}$ \\ ${ }^{1}$ State Key Laboratory of Integrated Management of Pest Insects and Rodents, Institute of Zoology, Chinese \\ Academy of Sciences, Beijing, China; ${ }^{2}$ Shandong Provincial Key Laboratory for Applied Microbiology, Ecology \\ Institute of Shandong Academy of Sciences, Jinan, China ${ }^{3}$ College of Life Science, Hubei University, Wuhan, \\ China; ${ }^{4}$ Institute of Health Sciences, Anhui University, Hefei, China and ${ }^{5}$ Key Laboratory of Tropical Forest \\ Ecology, Xishuangbanna Tropical Botanical Garden, Chinese Academy of Sciences, Menglun, China
}

\begin{abstract}
Interactions among microbial symbionts have multiple roles in the maintenance of insect-microbe symbiosis. However, signals mediating microbial interactions have been scarcely studied. In the classical model system of bark beetles and fungal associates, fungi increase the fitness of insects. However, not all interactions are mutualistic, some of these fungal symbionts compete for sugars with beetle larvae. How this antagonistic effect is alleviated is unknown, and recent research suggests potential roles of bacterial symbionts. Red turpentine beetle (RTB), Dendroctonus valens LeConte, is an invasive pest in China, and it leads to wide spread, catastrophic mortality to Chinese pines. In the symbiotic system formed by RTB, fungi and bacteria, volatiles from predominant bacteria regulate the consumption sequence of carbon sources D-pinitol and D-glucose in the fungal symbiont Leptographium procerum, and appear to alleviate the antagonistic effect from the fungus against RTB larvae. However, active components of these volatiles are unknown. We detected 67 volatiles by Gas Chromatography-Mass Spectrometer (GC-MS). Seven of them were identified as candidate chemicals mediating bacteria-fungus interactions, among which ammonia made $L$. procerum consume its secondary carbon source D-pinitol instead of its preferred carbohydrate D-glucose. In conclusion, ammonia regulated the consumption sequence of these two carbon sources in the fungal symbiont. The ISME Journal (2017) 11, 2809-2820; doi:10.1038/ismej.2017.131; published online 11 August 2017
\end{abstract}

\section{Introduction}

Microbial associates and insect hosts form complex symbiotic relationships (Wang et al., 2012, 2015; Cheng et al., 2016; Lu et al., 2016; Xu et al., 2016a), including mutualistic interactions (Harrington, 2005; Douglas, 2015; Li et al., 2015) and antagonistic ones (Hofstetter et al., 2006; Wang et al., 2013). For mutualistic and antagonistic interactions at evolutionary timescales, the interaction between microbial associates and insect hosts may shift in temporal and spatial dynamics (Herre et al., 1999; Bronstein et al., 2003; Georgelin and Loeuille, 2014). Particularly, symbiotic relationships may be indirectly affected by a third, or even fourth

Correspondence: M Lu or J Sun, State Key Laboratory of Integrated Management of Pest Insects and Rodents, Institute of Zoology, Chinese Academy of Sciences, 1 Beichen West Road, Chaoyang District, Beijing 100101, China.

E-mail: lumin@ioz.ac.cn or sunjh@ioz.ac.cn

${ }^{6}$ These authors contributed equally to this work.

Received 13 February 2017; revised 23 June 2017; accepted 4 July 2017; published online 11 August 2017 participator in a community context (Klepzig et al., 2001). For example, interactions among these microbial symbionts can alleviate or eliminate the antagonistic effect from microbial associates on insect hosts (Therrien et al., 2015; Zhou et al., 2016). However, key chemical signals that mediate the dynamic shift from antagonism to mutualism have received limited attention.

In symbiotic systems formed by filamentous fungi and bark beetles, fungal associates not only increase bark beetle fitness but also show antagonistic effects on insect hosts. For instance, fungal associates have roles in improving bark beetle nutrition (Ayres et al., 2000; Harrington, 2005), synthesizing beetle pheromone (Brand et al., 1976), and overcoming tree defense (Lee et al., 2006; Novak et al., 2015). In turn, insect hosts serve as transmission vectors for associated fungi (Lu et al., 2011). In contrast to beneficial effects of fungal associates on bark beetles, negative ones have also been reported. For example, fungi compete over saccharides with bark beetle larvae, which leads to slowed larval growth rates (Wang et al., 2013). In addition to fungal associates, a 
myriad of bacteria have also formed close symbiotic relationships with bark beetles (Brand et al., 1976; Morales-Jiménez et al., 2009; Adams et al., 2013; Boone et al., 2013; Jesús et al., 2013; Therrien et al., 2015; Xu et al., 2015, 2016b). Recent studies reveal that bacteria-derived volatiles have potential roles in mediating fungus-bark beetle interactions (Zhou et al., 2016).

Bacterial volatiles have been reported to affect activities of many associated organisms. They serve as growth and reproduction regulators for heterogeneous species, toxic chemicals to prokaryotes and nematodes, molecular signals in microbial chemical communication, and function as insect semiochemicals (Kai et al., 2009; Audrain et al., 2015). In the symbiotic system formed by bark beetles, bacteria and fungi, these volatiles could regulate fungal reproduction, as well as the mycelium growth (Adams et al., 2009), and mediate carbon allocation in this symbiosis (Zhou et al., 2016). However, no systematic studies have identified the specific active component of bacterial volatiles.

The red turpentine beetle (RTB), Dendroctonus valens LeConte, originates from North America and has led to catastrophic mortality to native pine trees in China (Sun et al., 2013). Its adult forms tight symbiotic relationships with the fungus Leptographium procerum, which contributes to its successful invasiveness in China ( $\mathrm{Lu}$ et al., 2009, 2011; Cheng et al., 2015). However, RTB larval growth is drastically inhibited by saccharide shortage caused by $L$. procerum and some other fungi (Wang et al., 2013). Further research revealed that consumption of one common carbon source D-glucose over another carbohydrate D-pinitol in pine phloem tissues by the fungus inhibit $D$. valens larval weight increase, whereas the dominant bacteria control the fungal sugar usage even though both bacteria and fungi are able to metabolize these sugars (Zhou et al., 2016). D-glucose is a better carbon source over D-pinitol not only for RTB larvae but also for associated fungi and bacteria. Thus, bacterial volatiles may have essential roles in maintaining this symbiotic system. However, active components of these bacterial volatiles are unknown, and the chemical signal(s) regulating carbon source usage in the fungus has not been determined. In this study, we determined the composition of volatiles produced by dominant $D$. valens bacterial symbionts and subsequently evaluated which active component regulated carbon consumption in L. procerum.

\section{Materials and methods}

Standards of 1,10-undecadiene, 2-butanol, 2-heptanone, 2,2-dimethyl-hexane, 3-methyl-1-butanol, $(R)$-2-hexanol, n-ethyl acetate were purchased from J\&K Scientific Ltd (Beijing, China, chromatography grade). Ammonia water solution (chromatography grade) was purchased from Xilong Chemical Co., Ltd (Shantou, China).
Bacteria were obtained by a culture-dependent isolation method described in previous research (Lou et al., 2014; Zhou et al., 2016). Larvae (ranging from 1 st to 5 th instar), larval guts and frass samples were immersed in $200 \mu \mathrm{l}$ of $10 \%$ phosphate-buffered saline, respectively, sonicated for $1 \mathrm{~min}$, and vortex for $10 \mathrm{~s}$. Then, $100 \mu \mathrm{l}$ of the suspension were plated on Luria-Bertani agar (LBA) containing $40 \mathrm{mg} \mathrm{l}^{-1}$ nystatin and $0.5 \mathrm{mg} \mathrm{l}^{-1}$ cycloheximide. Subsequently, these plates were incubated at $28^{\circ} \mathrm{C}$ for $12-48 \mathrm{~h}$. Colonies were selected to streak on LBA plates for purification and $16 \mathrm{~s}$ ribosomal DNA sequencing to identify bacterial species. Identified bacterial strains were maintained in glycerinum LB mixture (25:75) at $-80^{\circ} \mathrm{C}$. Among those bacterial species, isolation frequencies of Rahnella aquatilis, Serratia liquefaciens and Pseudomonas sp. 7 were higher than other species. Thus, one strain of the above each species including Serratia liquefaciens B310 (KR106612), Rahnella aquatilis B301 (KR106621) and Pseudomonas sp. 7 B321 (KR106607) were used. One fungal strain L. procerum CMW25626, commonly associated with RTB (Lu et al., 2009) and reported as antagonistic fungal associate for RTB larvae (Wang et al., 2013), was used.

Experiment I: effects of volatiles from $R$. aquatilis B301 on D-pinitol and D-glucose consumption order in L. procerum, and effects of bacteria on D. valens larval growth after feeding on fungus-colonized phloem media D-pinitol and D-glucose content in phloem media following fungus consumption were tested with or without $R$. aquatilis B301. Briefly, $90 \mathrm{~mm}$ Petri dishes were separated into two equal parts in the middle were used. L. procerum was inoculated on phloem media on one side of the Petri dish, and bacteria on LBA on the opposite side (treated group). In the control group, the LBA in Petri dishes was left blank. Sugar content in above phloem media were determined every 5 days (Zhou et al., 2016). Five replicates were used. Detailed information for carbohydrate quantification is in the Supplementary Methods.

Larval weight increase of $D$. valens fed with media colonized by fungus or not (control) were determined. Thirty-two replicates were used. In addition, effects of each bacterial strain (B301, B310 and B321) on larval weight increase of $D$. valens fed with media colonized by fungus were determined. Blank LBA plates were used instead of bacteria-colonized plates in the control group. Thirty-six replicates were used. Detailed information of this experiment is in Supplementary Methods.

Experiment II: effects of pine volatile, $\alpha$-pinene, on bacterial regulation of sugar usage order in the fungal symbiont L. procerum

In previous reports, eight bacterial strains associated with $D$. valens larvae were shown to alter the usage order of two carbon sources, D-glucose and D-pinitol 
in L. procerum under effects of $\alpha$-pinene (Zhou et al., 2016). Thus, the volatile component working on $L$. procerum possibly includes $\alpha$-pinene, its bacterially converted analogs or volatiles produced by bacteria. To rule out the effect of $\alpha$-pinene, two experiments were conducted. First, effects of $\alpha$-pinene on fungal growth and sugar usage in $L$. procerum were determined. Similar to Experiment I, Petri dishes separated into two parts were used. L. procerum was inoculated onto phloem media in one side of the Petri dish. Agilent glass vial inserts $(250 \mu \mathrm{l})$ containing 0 (control group), 4, 16, 64 and $200 \mu \mathrm{l}$ of $\alpha$-pinene sealed with sterile cotton were put into blank sides (opposite the fungi) in these Petri dishes. The phloem media were sampled at 30 days following fungus inoculation, and the amount of carbohydrate used up was calculated (Zhou et al., 2016). Nine replicates were used. Second, effects of three bacterial strains with high isolation frequency, including B301, B310 and B321, on growth and sugar usage order in L. procerum under the effect of $\alpha$-pinene or not (control) were determined. Specifically, identical arenas were used as in Experiment I, but with one change: one glass vial insert containing $200 \mu \mathrm{l}$ of $\alpha$-pinene (in the presence of $\alpha$-pinene) or an empty vial insert (in the absence of $\alpha$-pinene) sealed with sterile cotton was put inside the Petri dish. For both of those two experiments (in the presence or absence of $\alpha$-pinene), three bacterial strains were regarded as treatments, and LB agar plates free of bacteria were used as controls. Four replicates were used. Fungal growth as well as sugar content in phloem media were determined according to previously published protocols (Zhou et al., 2016). Detailed information is provided in Supplementary Methods. For each treatment of bacterial strain, fungal mycelium linear growth rate relative to controls, as well as the amount of D-glucose and Dpinitol used up was calculated.

\section{Experiment III: determination of candidate volatile} chemicals working on L. procerum CMW25626

Volatile profile of three selected bacterial strains, including B301, B310 and B321, were analyzed by solid phase micro-extraction-Gas ChromatographyMass Spectrometer (GC-MS) (Robacker et al., 2004; Behrends et al., 2011). Briefly, bacterial volatiles were sampled with solid phase micro-extraction and analyzed by GC-MS. Data files were analyzed with the automated mass spectral and identification system for peak deconvolution and spectra were matched using the NIST mass spectral library (NIST 2008) and a custom library. Then, the resulting files were combined with Common Data Format files from raw mass spectrum data and imported into Matlab (R2004a) for retention time correction and area integration across the data set with GC-MS Assignment Validator and Integrator. Subsequently, principal component analysis was conducted to reveal an overview of sample data distribution. Orthogonal partial least squares discriminant analysis (OPLSDA) was conducted to predict variable importance. Volatiles with variable importance in the projection $<0.5$ in OPLS-DA were regarded as preliminary potential chemicals, and statistic difference of their peak areas was analyzed with analysis of variance (ANOVA) by IBM SPSS Statistics 21.0 (International Business Machines Corp., Armonk, NY, USA). Among these chemicals, those without statistical significance were regarded as candidate chemicals, which may affect $L$. procerum and regulate its carbon source usage order. For each of the bacterial strains, eight replications were set, and LBA was used as control. Detailed information is in Supplementary Methods.

Experiment IV: effects of candidate volatile chemicals on the fungal growth and sugar usage order in

L. procerum

Before bioassay, all candidate chemicals were conclusively identified by comparison of retention time and total ion chromatogram with authentic standards. Petri dishes that were separated into two parts were used. Fungi were inoculated on phloem media on one side of the Petri dish. The opposite side was left blank to release volatile chemicals. Agilent glass vial inserts $(250 \mu \mathrm{l})$ containing 0 (control group), 4 , 16, 64 and $200 \mu \mathrm{l}$ of each candidate chemical standard (except ammonia) sealed with sterile cotton were put into blank sides (opposite the fungi) in these Petri dishes. Standard ammonia water solution (18.67 $\mathrm{mol} \mathrm{l}^{-1}$ ) instead of its pure chemical was used. As the ammonia concentration in RTB gallery was not available to be tested, the purchased solution was diluted across a range of concentrations $(0.07,0.26$, 1.17 and $4.67 \mathrm{~mol} \mathrm{l}^{-1}$ ). In all, $200 \mu \mathrm{l}$ of above diluted solution inside a vial insert was put into the opposite side of fungi in these Petri dishes. Sterile water was used in the control group. Each dose of these chemicals, including ammonia solution, was repeated nine times. The linear fungal growth was measured every 2 days. The two selected carbon sources consumed in plates were measured 15 days later, and values were calculated and shown as percent proportion of total original D-pinitol or Dglucose. Detailed procedures on this section are in the Supplementary Methods.

Experiment $V$ : effects of $L B$ bacterial cultures and ammonia water solution on the growth and the carbon consumption of L. procerum CMW25626

Experiment IV results revealed that the bacterial volatile, ammonia, can alter the carbon source usage order in L. procerum. As ammonia can dissolve into water, this chemical was absorbed by LB agar and phloem media in previous experiments and could not be readily quantified. Here, two experiments were conducted to quantify ammonia produced by bacteria and to validate the effect of ammonia water 
solution on $L$. procerum. First, effects of volatiles from liquid LB bacterial cultures on growth and the sugar usage order in $L$. procerum were determined in similar arenas as described previously. Three bacterial strains, including B301, B310 and B321, which had also been selected for solid phase microextraction-GC-MS analyses, were used. Specifically, L. procerum was inoculated on phloem media $(10 \mathrm{ml})$ in one side of the separated Petri dish. In all, $10 \mathrm{ml}$ of liquid LB was inoculated with $4 \mu \mathrm{l}$ of actively growing bacterial cultures on the other sides of the Petri dish. Then, the Petri dish was sealed and kept at $25{ }^{\circ} \mathrm{C}$. Fungal growth as well as content of Dglucose and D-pinitol in plates was measured as described previously. LB cultures without bacterial inoculation were set as the control group. Five replicates were used. Second, effects of ammonia water solution containing similar ammonia concentration with bacterial LB cultures on $L$. procerum were determined. Specifically, according to the ammonia concentration measured in bacterial LB cultures at 12, 24, 48 and $72 \mathrm{~h}$ (Supplementary Figure S1), standard ammonia water solution $\left(\approx 18.67 \mathrm{~mol} \mathrm{l}^{-1}\right)$ was diluted to $0.39,0.78,1.56$ and $3.12 \mathrm{~mol} \mathrm{l}^{-1}$. Effects of these diluted ammonia water
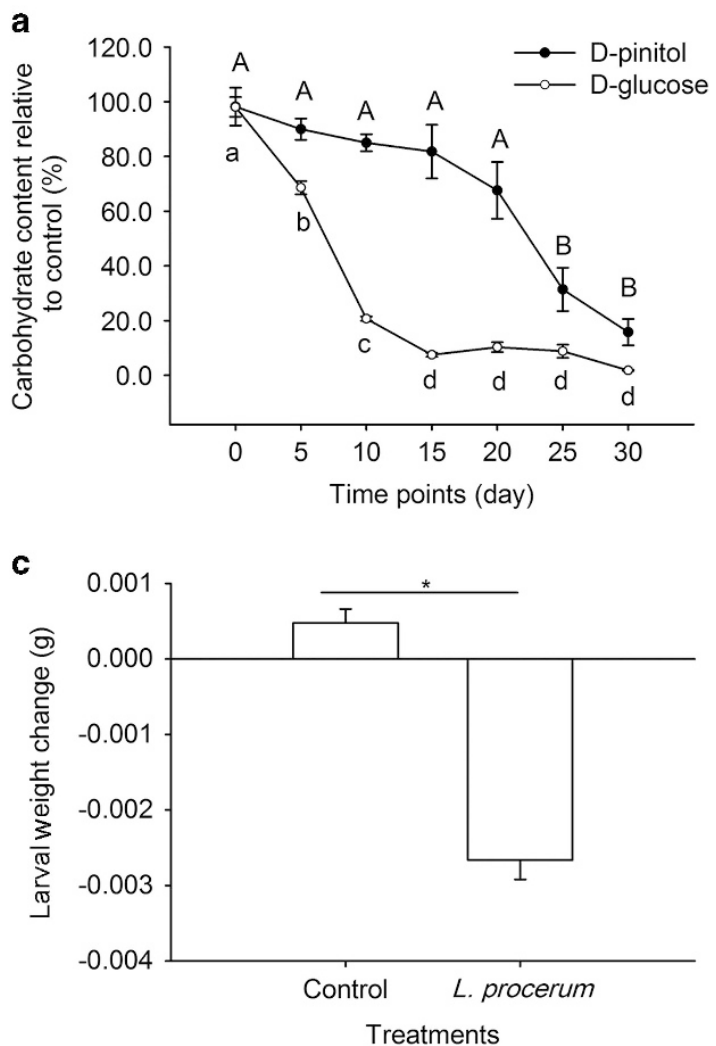

solution on growth and carbon source usage order in L. procerum was determined with identical arenas used as described in Experiment IV. Sterilized distilled water was used as control. There were nine replicates of each treatment. We measured the fungal growth and consumed D-glucose and D-pinitol in plates as described previously.

\section{Data analysis}

Kolmogorov-Smirnov test was conducted to test the normality of all variables before data analysis. In addition, Levene's test was also conducted to test homogeneity of group variances. In Experiment I, specific carbon source content was used as dependent variable, and time points were used as independent variables in Welch's (Dunnett's T3 test for unequal variances) or one-way ANOVA (Tukey's test for equal variances). Larval weight changes that were influenced by $L$. procerum were analyzed with independent-samples $t$-test. Larval weight changes that were influenced by three bacterial strains (B301, B310 and B321) were compared using one-way ANOVA (Tukey's test). In Experiment II, fungal growth, carbon source consumption was used as
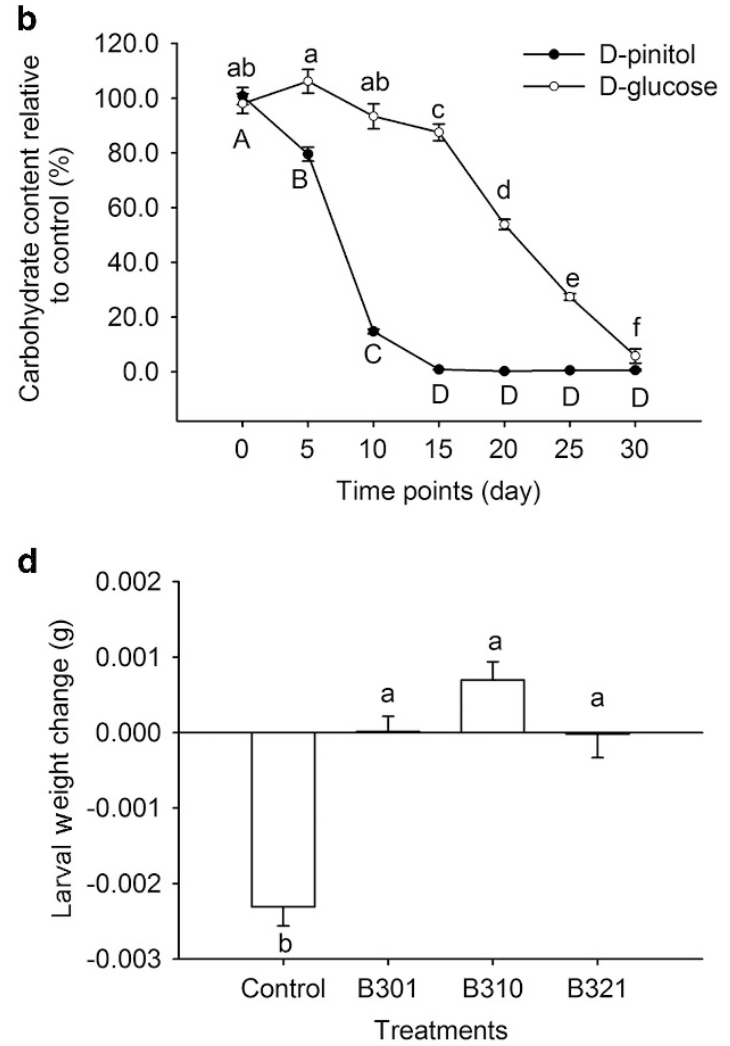

Figure 1 Experiment I: carbohydrate composition in phloem media at different points in time after L. procerum growth without (a) and with (b) R. aquatilis B301. Average weight change of RTB larvae during a 6- day period after feeding on: (c) the control (sterile media) and the media with $L$. procerum, (d) the control (L. procerum-colonized media) and $L$. procerum-colonized media in the presence of three bacterial strains. Carbohydrate consumption in fungus-grown phloem media was represented as carbohydrate content left relative to fungus-free phloem media. Different letters within each group of bars refer to significant difference (capital letters for D-pinitol in Figures 1a and b, and lowercase letters for larval weight change and D-glucose in Figures 1a, b and d). '*' between the two connected bars in Figures 1c signify a significant difference. 
dependent variables, and $\alpha$-pinene doses in the first experiment and bacterial strains in the second experiment were treated as independent variables in oneway ANOVA (Tukey's test for equal variances) or Welch's ANOVA test (Dunnett's T3 test for unequal variances). In Experiment III, multivariable analysis of volatile peak areas was analyzed with SIMCA-P 13.0 (Sartorius Stedim Biotech, Umeå, Sweden). For preliminary potential chemicals, the difference in the relative abundance of volatiles was analyzed using one-way ANOVA (Tukey's test). In Experiment IV, for each chemical, the difference of fungal growth and carbon source contents from different chemical doses was analyzed using Welch's ANOVA (Dunnett's T3 test for unequal variances) or one-way ANOVA (Tukey's test for equal variances). Data with nonnormal distribution were compared with the KruskalWallis test followed by Mann-Whitney $U$-test using Bonferroni correction to adjust the probability. In Experiment V, the difference of fungal growth, as well as specific carbon source composition from bacterial strains in the first experiment and ammonia concentration in the second experiment were compared with Welch's ANOVA (Dunnett's T3 test for unequal variances) or one-way ANOVA (Tukey's test for equal variances). All figures of this study were produced with Sigmaplot 12.5 (Systat Software, Inc., San Jose, CA, USA).

\section{Results}

Experiment I: bacterial symbionts reduce inhibition of L. procerum on RTB larval weight increase by altering carbon source usage order in the fungus

Without the bacteria, D-pinitol composition (Figure 1a, one-way ANOVA, $F_{6,28}=19.193, P<0.001$ ), as well as D-glucose composition (Figure 1a, Welch's ANOVA, $\left.F_{6,11.166}=338.584, P<0.001\right)$ decreased significantly with time going on in plates colonized by $L$. procerum. D-glucose in plates colonized by L. procerum started to decline significantly on the fifth day. However, the content of D-pinitol stayed constant before the 20th day. With bacteria, D-pinitol (Figure 1b, Welch's ANOVA, $\left.F_{6}, 11.758=764.995, P<0.001\right)$ and D-glucose content (Figure 1b, one-way ANOVA, $F_{6,28}=144.056$, $P<0.001)$ also decreased significantly with time going on in plates colonized by L. procerum. Differently, D-glucose did not start to decline significantly until the 15th day. D-pinitol started to decline on day 5.

Weight of $D$. valens larva fed with media colonized by $L$. procerum declined significantly compared with fungus-free phloem media (Figure 1c, $d f=62, t=9.915$, $P<0.001$ ). Weight increase of $D$. valens larva fed with media colonized by L. procerum with three bacterial strains presented were significantly high compared with those without bacteria presented (Figure 1d, one-way ANOVA, $\left.F_{3,140}=26.597, P<0.001\right)$.
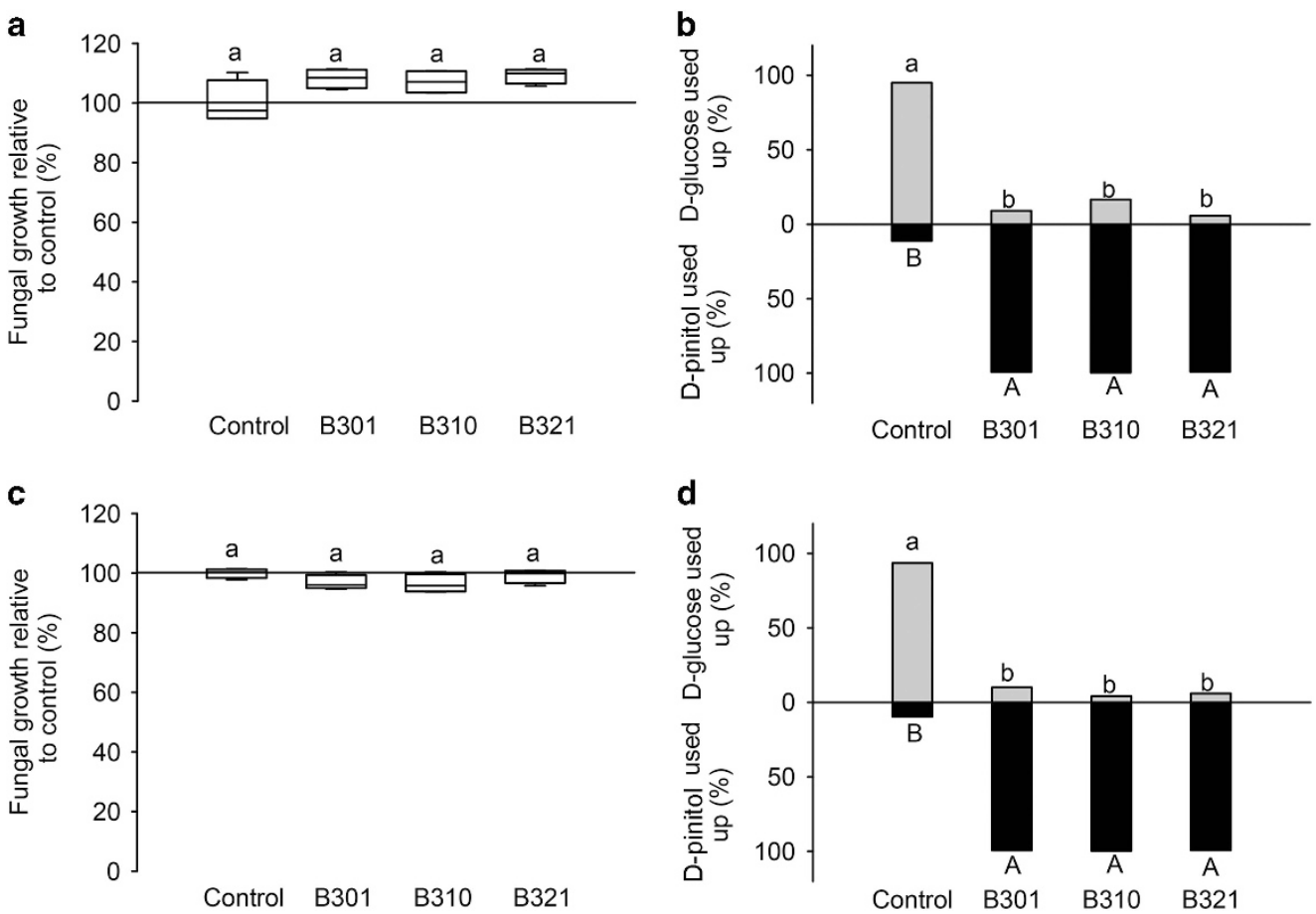

Figure 2 Experiment II: effects of bacterial volatiles on growth and consumption of D-pinitol and D-glucose in $L$. procerum in the presence $(\mathbf{a}, \mathbf{b})$ or absence $(\mathbf{c}, \mathbf{d})$ of $\alpha$-pinene. L. procerum CMW25626 growth (a) and consumption of D-pinitol and D-glucose in phloem media (b) in the presence of $\alpha$-pinene and bacterial volatiles; L. procerum CMW25626 growth (c) and consumption of D-pinitol and D-glucose in phloem media (d) in the presence of bacterial volatiles in absence of $\alpha$-pinene. The top of $Y$ axis in (b) and (d) refers to proportion of D-glucose used up, and the bottom refers to proportion of D-pinitol used up. Different letters above each bar refer to significant difference of multiple comparisons (capital letters for D-pinitol in Figures $2 b$ and $d$; lowercase letters for D-glucose in Figures $2 b$ and $d$ and fungal growth in Figures 2a and c). 

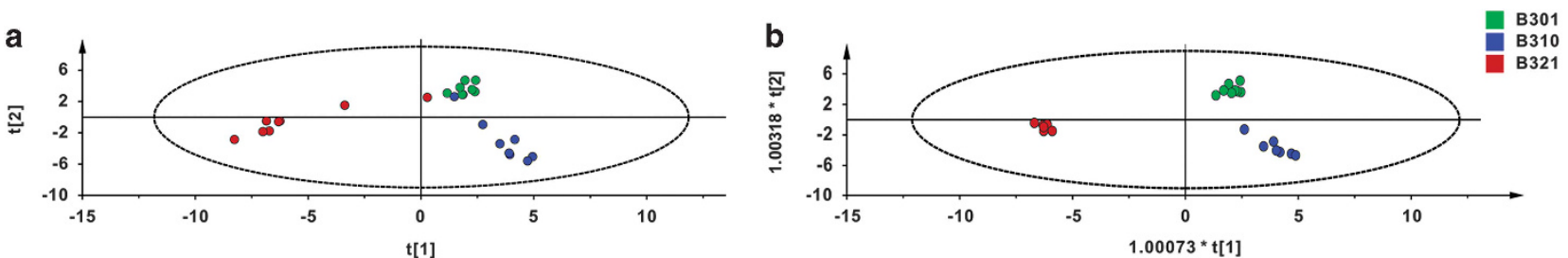

C

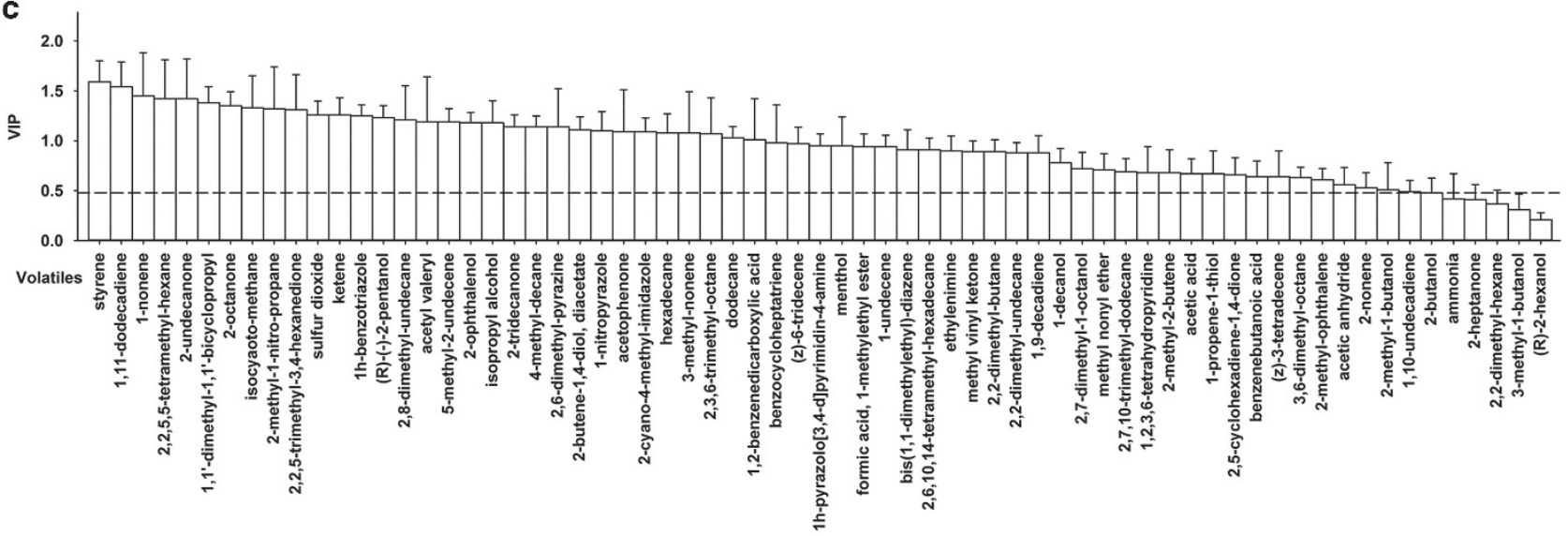

Figure 3 Experiment III: principal component analysis (PCA) analysis (a) and OPLS-DA analysis (b) of volatile samples derived from bacterial strains $R$. aquatilis B301 (green dots), S. liquefaciens B310 (blue dots) and Pseudomonas sp. 7 B321 (red dots) associated with D. valens larvae and variable importance for the projection (VIP) values of 67 volatiles in OPLS-DA (c). The dashed ellipse line represents $95 \%$ confidence intervals.

Experiment II: pine tree volatile, $\alpha$-pinene, showed no effects on bacterial regulation of sugar usage order in L. procerum

Pine tree volatile $\alpha$-pinene did not affect $L$. procerum growth (Supplementary Figure S2a, one-way ANOVA, $F_{4,40}=1.316, P=0.281$ ). In addition, both D-glucose (Supplementary Figure S2b, one-way ANOVA, $\left.\quad F_{4,} \quad 40=1.292, \quad P=0.289\right)$ and D-pinitol (Supplementary Figure S2b, one-way ANOVA, $F_{4,40}=0.940, P=0.451$ ) used up in plates colonized by $L$. procerum were not affected by $\alpha$-pinene.

In the presence of $\alpha$-pinene, the three selected bacterial strains, including B301, B310 and B321, did not affect fungal growth (Figure 2a, one-way ANOVA, $\left.F_{3,12}=3.272, P=0.059\right)$. In addition, proportions of both D-glucose (Figure 2b, one-way ANOVA, $F_{3, \quad 12}=9.127, P<0.05$ ) and D-pinitol (Figure 2b, Welch's ANOVA, $F_{3,5.164}=55.856, P<0.05$ ) used up in fungus-grown plates were significantly influenced by the selected bacteria. Less than $20 \%$ of D-glucose in fungus-colonized plates under the effects of bacteria was used up, whereas almost all of that carbohydrate was consumed in control group. In contrast, almost all of D-pinitol in fungus-colonized plates under effects of bacteria was used up, whereas only $10.5 \%$ of that carbohydrate was consumed in the control group.

In the absence of $\alpha$-pinene, three selected bacterial strains, including B301, B310 and B321, did not affect fungal growth (Figure 2c, one-way ANOVA, $\left.F_{3,12}=2.078, P=0.157\right)$. However, both D-glucose (Figure 2d, one-way ANOVA, $F_{3,12}=9.006, P<0.05$ ) and D-pinitol (Figure 2d, Welch's ANOVA,
$\left.F_{3, \quad 5.293}=209.252, \quad P<0.05\right)$ used up in funguscolonized plates was significantly influenced selected bacteria. Similarly with carbon consumption in the presence of $\alpha$-pinene, D-pinitol was used up before D-glucose started to be consumed by $L$. procerum in the absence of $\alpha$-pinene.

Experiment III: seven candidate volatile chemicals working on L. procerum CMW25626

In total, there were 67 volatile chemicals detected, and these chemicals were generally assigned to chemical groups such as alcohol, alkene, alkane, ketone, ester, acid, N-containing chemicals, S-containing chemicals and others (Supplementary Table S1). Figure 3a showed that all samples from three bacterial strains were all inside the 95\% confidence intervals in principal component analysis. The non-supervised model revealed that the majority of samples from three bacterial strains clustered separately from each other except for three samples. Samples from R. aquatilis B301 were close to that from S. liquefaciens B310. Both of them were shifted away from that of Pseudomonas sp. 7 B321. This analysis showed that volatile profiling could reflect differences among volatiles from different bacterial species, and all sample data could be used for further OPLS-DA.

OPLS-DA showed maximum discrimination of three experimental groups (Figure 3b). All samples were clustered into three groups and each group of samples was statistically different. Besides, the OPLS-DA model could reflect $96.7 \%\left(\mathrm{R}^{2} \mathrm{Y}\right)$ and 
Table 1 Relative abundance of seven candidate volatiles (VIP $<0.5$ in OPLS-DA model) derived from bacterial strains associated with D. valens larvae

\begin{tabular}{|c|c|c|c|c|c|c|}
\hline \multirow[t]{2}{*}{ Volatiles } & \multicolumn{3}{|c|}{ Bacterial strains } & \multirow[t]{2}{*}{$d f$} & \multirow[t]{2}{*}{$F$} & \multirow[t]{2}{*}{ P-value } \\
\hline & B301 & $B 310$ & B321 & & & \\
\hline 3-Methyl-1-butanol & $1.04 \mathrm{E}-08 \pm 1.40 \mathrm{E}-06 \mathrm{a}$ & $1.04 \mathrm{E}-08 \pm 1.09 \mathrm{E}-06 \mathrm{a}$ & $1.03 \mathrm{E}-08 \pm 1.21 \mathrm{E}-06 \mathrm{a}$ & $(2,21)$ & 0.344 & 0.713 \\
\hline 1,10-Undecadiene & $2.55 \mathrm{E}-05 \pm 5.08 \mathrm{E}-04 \mathrm{a}$ & $1.96 \mathrm{E}-05 \pm 3.04 \mathrm{E}-04 \mathrm{a}$ & $3.07 \mathrm{E}-05 \pm 4.19 \mathrm{E}-04 \mathrm{a}$ & $(2,21)$ & 1.779 & 0.193 \\
\hline 2-Butanol & $4.97 \mathrm{E}-06 \pm 5.50 \mathrm{E}-05 \mathrm{a}$ & $6.07 \mathrm{E}-06 \pm 2.26 \mathrm{E}-05 \mathrm{a}$ & $1.39 \mathrm{E}-07 \pm 7.74 \mathrm{E}-06 \mathrm{a}$ & $(2,21)$ & 1.185 & 0.325 \\
\hline 2-Heptanone & $1.02 \mathrm{E}-06 \pm 1.67 \mathrm{E}-05 \mathrm{a}$ & $9.98 \mathrm{E}-05 \pm 1.60 \mathrm{E}-05 \mathrm{a}$ & $1.94 \mathrm{E}-06 \pm 9.70 \mathrm{E}-05 \mathrm{a}$ & $(2,21)$ & 0.881 & 0.429 \\
\hline 2,2-Dimethyl-hexane & $7.68 \mathrm{E}-07 \pm 7.06 \mathrm{E}-06 \mathrm{a}$ & $6.45 \mathrm{E}-07 \pm 8.48 \mathrm{E}-05 \mathrm{a}$ & $7.53 \mathrm{E}-07 \pm 8.99 \mathrm{E}-06 \mathrm{a}$ & $(2,21)$ & 1.038 & 0.372 \\
\hline (R)-2-hexanol & $6.82 \mathrm{E}-05 \pm 1.49 \mathrm{E}-04 \mathrm{a}$ & $6.64 \mathrm{E}-05 \pm 1.14 \mathrm{E}-04 \mathrm{a}$ & $6.75 \mathrm{E}-05 \pm 1.41 \mathrm{E}-04 \mathrm{a}$ & $(2,21)$ & 0.450 & 0.644 \\
\hline Ammonia & $1.27 \mathrm{E}-09 \pm 1.26 \mathrm{E}-08 \mathrm{a}$ & $1.37 \mathrm{E}-09 \pm 2.57 \mathrm{E}-08 \mathrm{a}$ & $1.05 \mathrm{E}-09 \pm 2.05 \mathrm{E}-07 \mathrm{a}$ & $(2,21)$ & 0.950 & 0.403 \\
\hline
\end{tabular}

Abbreviations: OPLS-DA, orthogonal partial least squares discriminant analysis; VIP, variable importance in the projection.
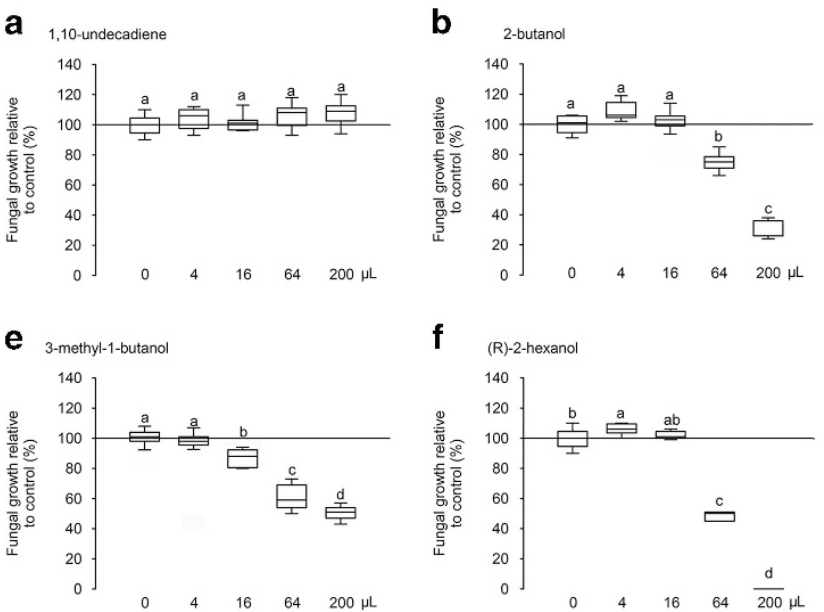

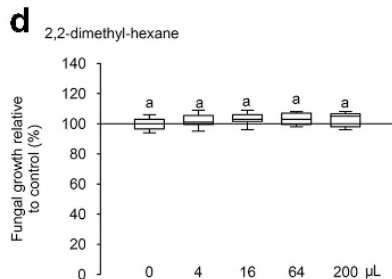

g

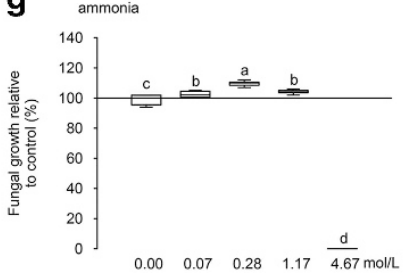

Figure 4 Experiment IV: effects of 7 bacterial volatiles on the growth of L. procerum CMW25626. Figures 4a-g refer to the L. procerum CMW25626 growth rate relative to control (in percent) in the presence of volatiles 1,10-undecadiene (a), 2-butanol (b), 2-heptanone (c), 2,2-dimethyl-hexane (d), 3-methyl-1-butanol (e), (R)-2-hexanol (f) and ammonia (g), respectively. Different letters above each bar refer to significant difference of multiple comparisons.

predict $92.5 \%\left(Q^{2} Y\right)$ of the data set. Seven volatile chemicals with variable importance in the projection $<0.5$ (Figure 3c,Supplementary Table S2) from 67 chemicals were tested for statistical significance, and each of these seven volatile chemicals showed no significant difference among three bacterial strains (Table 1). These results indicated that the seven volatile chemicals may be active chemicals.

Experiment IV: effects of candidate volatile chemicals on the growth and the consumption order of D-glucose and D-pinitol in L. procerum CMW25626

The compounds 1, 10-undecadiene (Figure 4a, oneway ANOVA test, $\left.F_{4,40}=2.063, P=0.104\right)$ and 2 , 2dimethyl-hexane (Figure 4d, one-way ANOVA, $\left.F_{4,}{ }_{40}=0.800, \quad P=0.532\right)$ showed no effects on $L$. procerum growth. In contrast, 2-butanol (Figure 4b, one-way ANOVA test, $F_{4,40}=77.021$, $P<0.001$ ), 2-heptanone (Figure 4c, one-way ANOVA test $\left.\quad F_{4,40}=4.712, \quad P<0.05\right), \quad 3$-methyl-1-butanol (Figure 4e, one-way ANOVA, $F_{4,}, 40=34.846$, $P<0.001$ ), (R)-2-hexanol (Figure 4f, Kruskal-Wallis test, $H=36.755, P<0.001$ ) and ammonia (Figure $4 \mathrm{~g}$,
Kruskal-Wallis test, $H=40.662, P<0.001)$ showed dose-dependent inhibition on $L$. procerum growth.

For D-pinitol and D-glucose consumption, six volatile chemicals including 1, 10-undecadiene (Figure 5a, one-way ANOVA test, $F_{4,40}=0.907$, $P=0.469$ ), 2-butanol (Figure 5b, one-way ANOVA test, $F_{4,40}=1.434, P=0.271$ ), 2-heptanone (Figure 5c, Welch's ANOVA test, $F_{4,19.257}=0.216, P=0.901$ ), 2 , 2-dimethyl-hexane (Figure $5 \mathrm{~d}$, one-way ANOVA test, $\left.\quad F_{4,} \quad 40=1.843, \quad P=0.140\right), \quad 3$-methyl-1-butanol (Figure 5e, Welch's ANOVA test, $F_{4,17.957}=1.710$, $P=0.139$ ) and (R)-2-hexanol (Figure 5f, Welch's ANOVA test, $\left.F_{4,17.593}=1.154, P=0.056\right)$ showed no significant effects on the D-pinitol consumption by L. procerum. This fungus consumed $0-15.0 \%$ of D-pinitol in the media in the presence of each of these six chemicals. Two chemicals 1, 10undecadiene (Welch's ANOVA test, $F_{4,18.130}=2.021$, $P=0.107$ ) and 2, 2-dimethyl-hexane (one-way ANOVA test, $F_{4,40}=1.120, P=0.361$ ) showed no significant effects on fungal consumption of D-glucose as the fungus consumed $96.5-97.6 \%$ of D-glucose in the plate. Four chemicals including 2-butanol (Welch's ANOVA test, $F_{4,16.571}=74.547$, 

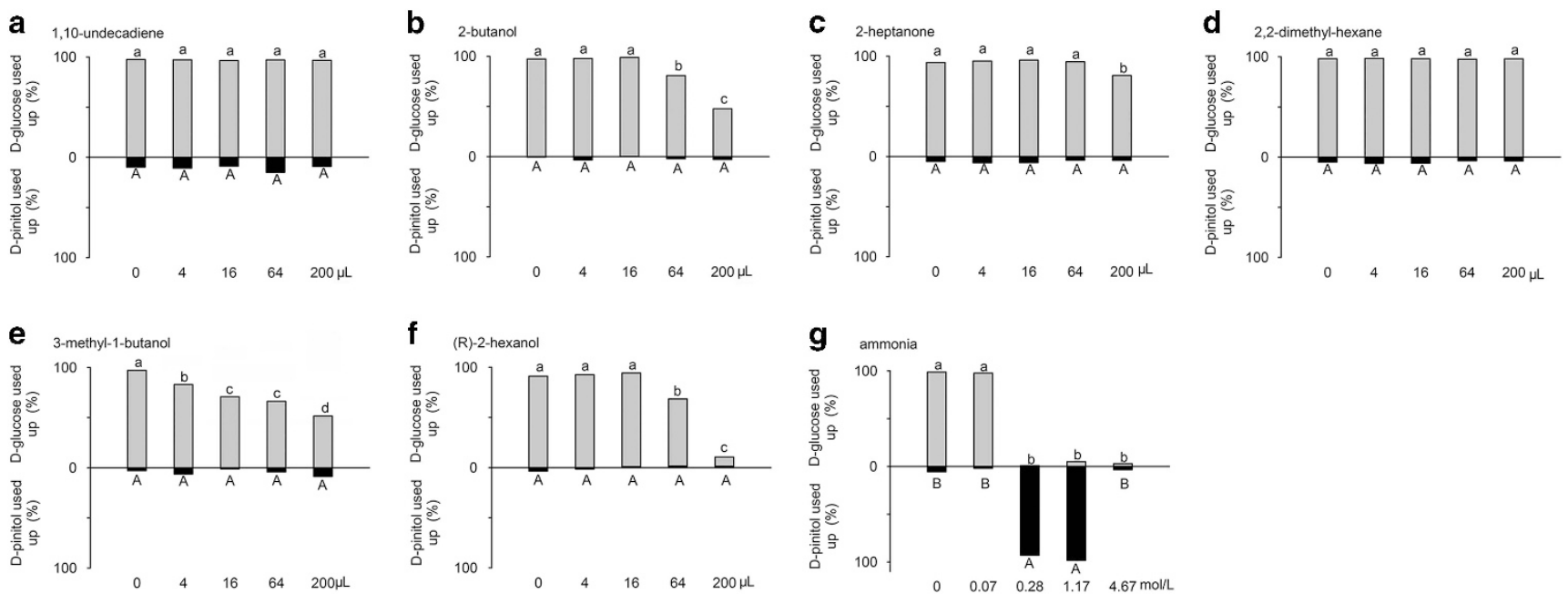

Figure 5 Experiment IV: effects of seven bacterial volatiles on the D-pinitol and D-glucose consumption sequence of $L$. procerum CMW25626. Figures 5a-g refer to the D-pinitol and D-glucose proportion used up in fungus-grown media relative to fungus-free phloem media in the presence of volatiles 1,10-undecadiene (a), 2-butanol (b), 2-heptanone (c), 2,2-dimethyl-hexane (d), 3-methyl-1-butanol (e), (R)-2-hexanol (f), and ammonia (g), respectively. The top of $Y$ axis refers to proportion of D-glucose used up, and the bottom refers to proportion of D-pinitol used up. Different letters above each bar refer to significant difference of multiple comparisons within each set of bars (capital letters for D-pinitol, and lowercase letters for D-glucose).
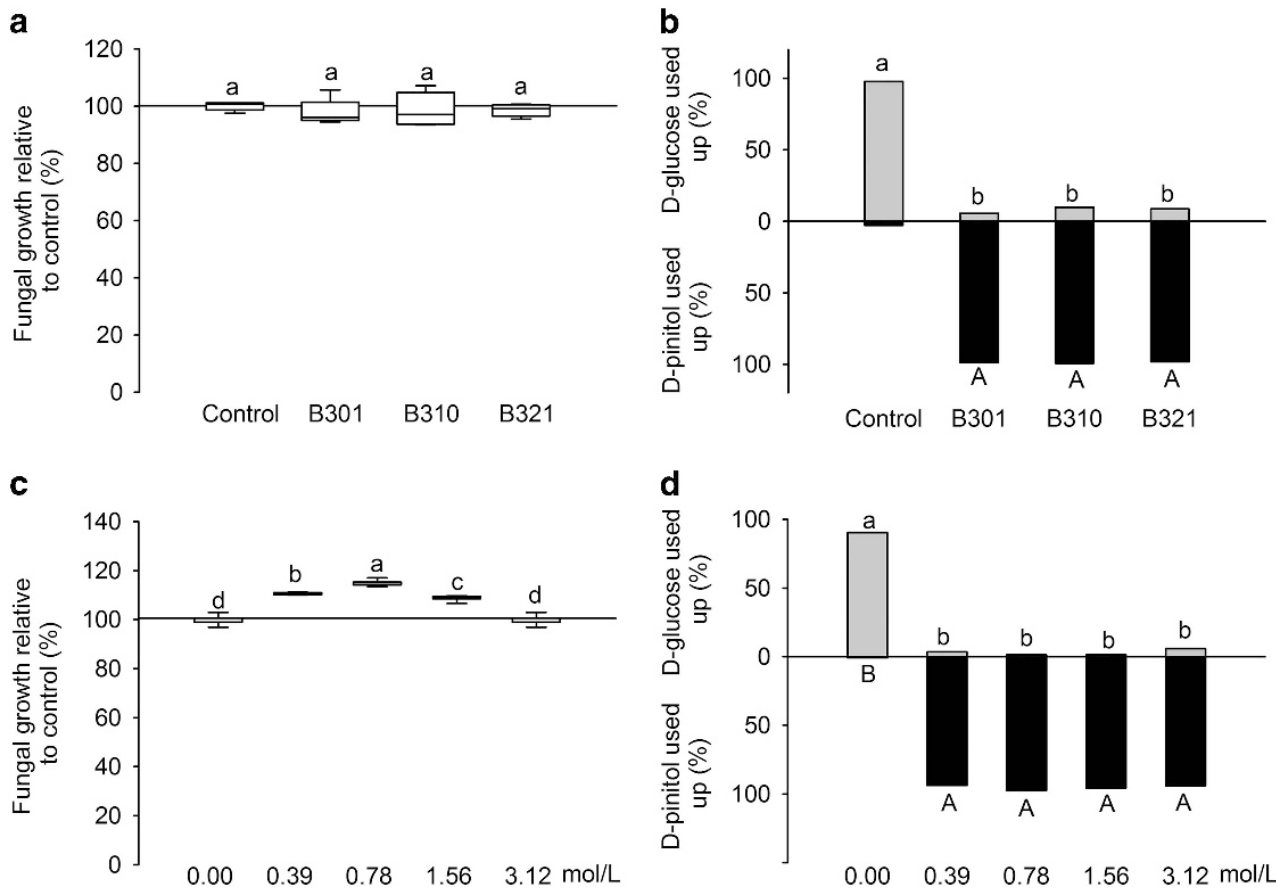

Figure 6 Experiment V: the growth (a), the D-pinitol and D-glucose consumption (b) in L. procerum CMW25626 in the presence of volatiles derived from LB bacterial cultures; the growth (c), D-pinitol and D-glucose consumption (d) in L. procerum CMW25626 in the presence of diluted ammonia water solution. The top of $Y$ axis in (b) and (d) refers to proportion of D-glucose used up, and the bottom refers to proportion of D-pinitol used up. Different letters refer to significant difference of multiple comparisons (capital letters for D-pinitol and lowercase letters for fungal growth and D-glucose).

$P<0.05$ ), 2-heptanone (Welch's ANOVA test, $F_{4}$ $16.845=26.723, P<0.05)$, 3-methyl-1-butanol (Welch's ANOVA test, $\left.F_{4,18.307}=12.590, P<0.05\right),(\mathrm{R})-2$-hexanol (Welch's ANOVA test, $F_{4}, \quad 18.358=225.058$, $P<0.05)$ slightly inhibited D-glucose consumption by $L$. procerum except for the treatment at dose of $200 \mu \mathrm{l}$ of (R)-2-hexanol. L. procerum consumed $47.7-98.9 \%$ of D-glucose in the media except for the treatment of $200 \mu \mathrm{l}$ of (R)-2-hexanol. Thus, D-glucose was consumed before D-pinitol started to be consumed by L. procerum under the effect of each of these six chemicals.

However, both D-pinitol (Figure 5g, Welch's ANOVA test, $\left.F_{4, \quad 17.121}=214.476, \quad P<0.001\right)$ and D-glucose (Figure 5g, Welch's ANOVA test, $F_{4,}{ }_{17.401}=112.761$, $P<0.001)$ consumption in fungus-grown phloem 
media were strongly affected significantly by ammonia. Under treatments of ammonia at doses of 0.26 and $1.17 \mathrm{~mol} \mathrm{l}^{-1}$, only $0.8 \%$ and $5.1 \%$ of D-glucose were consumed, whereas almost $100 \%$ of that carbohydrate was consumed in phloem media under treatments of ammonia at doses of 0.00 (control) and $0.07 \mathrm{~mol} \mathrm{l}^{-1}$, respectively. In contrast, under treatments of ammonia at higher doses of 0.26 and $1.17 \mathrm{~mol} \mathrm{l}^{-1}$, almost $100 \%$ of D-pinitol was consumed, whereas only $5.5 \%$ and $2.0 \%$ of that carbohydrate was consumed in phloem media under treatments of ammonia at doses of 0.00 (control) and $0.07 \mathrm{~mol} \mathrm{l}^{-1}$, respectively. D-glucose and D-pinitol were minimally consumed in funguscolonized plates under treatment of ammonia at the dosage of $4.67 \mathrm{~mol} \mathrm{l}^{-1}$, which was due to fungal growth inhibition.

Experiment V: ammonia produced from bacterial $L B$ cultures altered the sugar consumption order in L. procerum CMW25626

Bacterial LB cultures of strains B301, B310 and B321 did not affect the overall growth of $L$. procerum (Figure 6a, one-way ANOVA, $F_{3,}{ }_{16}=1.723$, $P=0.203$ ). Under the effects of three bacterial strains, almost all D-pinitol was used up in fungus-grown phloem media, whereas only $2.76 \%$ of that carbohydrate was consumed in the control group (Figure 6b, Welch's ANOVA, $\left.F_{3,} 15.123=645.954, P<0.001\right)$. In contrast, $<10 \%$ of $\mathrm{D}$-glucose was consumed in fungus-grown phloem media under effects of three bacterial strains, whereas $>97 \%$ of that carbohydrate was used up in the control group (Figure 6b, Welch's ANOVA, $F_{3,13.370}=166.898, P<0.001$ ).

Ammonia water solution significantly affected the growth of L. procerum (Figure 6c, one-way ANOVA test, $F_{4,40}=2.905, P<0.05$ ). The fungal growth rate was $110.5 \%, 125.8 \%, 105.7 \%$ and $101.8 \%$ compared with the control at doses of $0.39,0.78,1.56$ and $3.13 \mathrm{~mol} \mathrm{l}^{-1}$, respectively. Both the proportions of D-pinitol (Figure 6d, Welch's ANOVA test, $\left.F_{4}, \quad 19.053=1043.285, \quad P<0.001\right) \quad$ and $\quad$ D-glucose (Figure 6d, Welch's ANOVA test, $F_{4,}{ }_{18.833}=265.332$, $P<0.001$ ) used up in fungus-colonized plates were significantly affected by ammonia. Almost all of the D-pinitol in plates was consumed under the simulated effect of the presence of bacterial strains, whereas the same carbohydrate basically went unconsumed in the control group. In contrast, $<5.86 \%$ of D-glucose was consumed in phloem media under effects of bacterial volatiles, whereas $>90.3 \%$ of that carbohydrate was used up in the control group.

\section{Discussion}

Bacteria alleviated antagonistic effects of $L$. procerum on RTB larval growth with bacterial volatiles in the bark beetle-fungus symbiosis (Figure 1). In total, there were 67 volatile chemicals detected in the headspace of cultures of three selected bacterial strains B301, B310 and B321. Among these chemicals, seven of them, including 3-methyl-1-butanol, 1,10-undecadiene, 2-butanol, 2-heptanone, 2,2dimethyl-hexane, (R)-2-hexanol and ammonia, were deduced as candidate chemicals by variable importance in the projection analysis in OPLS-DA and ANOVA. These were evaluated further and used to test their effects on $L$. procerum. All these chemicals were commonly detected in volatile profiles of various bacterial species (Lemfack et al., 2014). Among those seven chemicals, the relative abundance of ammonia was higher than those of all the other chemicals (Supplementary Table S1), and further results revealed that it was ammonia that regulated the consumption order of D-glucose and Dpinitol in L. procerum (Figure 5).

Ammonia has been reported as intracellular signals and mediators of interspecific interactions. For example, it has been reported as the intracellular signal in altering fungal morphological switch. Arthrobotrys oligospora forms nest-like structures for nematode capture under effects of ammonia (Wang et al., 2014). In bacteria-fungus interactions, this chemical shows antifungal activity against Pythium preemergence (Howell et al., 1988), Botrytis cinerea and Penicillum nigricans (Schippers et al., 1982), and some other soil fungi (Eno et al., 1955). In addition, ammonia is essential for some fungi to develop fruit bodies (Sagara, 1975). In this study, ammonia not only affected the consumption order of D-pinitol and D-glucose in L. procerum but also altered fungal morphology. Normally, this fungus begins to form spores and its hyphae become gray after 10 days of cultivation on phloem media. However, its hyphae became white in the presence of ammonia (Supplementary Figure S4). This phenomenon indicated a systemic alteration of metabolism in that fungus. This is the first report that ammonia alters carbon consumption in fungi.

Ammonia is widely distributed in various ecosystems, and it is commonly produced by various bacteria (Bladen et al., 1961; van Steenbergern et al., 1986; Bernier et al., 2011). Ammonia is generated through total organic nitrogen by microbial ammonification (Moir, 2011), and the most common pathway for ammonia production is deamination of amino acid (Berg et al., 2002). This chemical has not attracted much attention from researchers that focused on microbial volatiles for various reasons. First, this chemical is very common in various natural ecosystems. Second, the molecular weight of ammonia is 17 , which is lower than that of most solvents used in liquid-liquid extraction. During the GC-MS analysis of liquid samples, the ammonia peak elutes before the solvent peak, and both of them could not be detected because of the solvent delay time. Third, the mass scanning range is usually set starting from 32 atomic mass unit to negate effects of nitrogen and oxygen in solid phase micro-extraction-GC-MS analysis. As a result, ammonia is usually excluded. In this study, the mass 
scanning range was set from 0 to 550 atomic mass unit in order to detect sufficient peak signals from ammonia. As solid phase micro-extraction was used instead of liquid-liquid extraction, it was possible to immediately turn on the detector without solvent delay. However, as the molecular weight of ammonia and water are so close to each other, their total ion chromatogram peaks overlapped during GC-MS analysis. Therefore, the peak area of ammonia had to be recalculated by using data from extracted ion chromatograms.

In contrast to other signal chemicals such as the bacterial volatile 2,3-butanediol that promotes plant growth (Ryu et al., 2003), volatiles that altered the consumption order of D-pinitol and D-glucose in $L$. procerum could be assimilated by that fungus as a nitrogen source in this study (Supplementary Figure S3). This is of great significance for the bark beetle-microbe symbiosis inhabiting barren barks, a habitat which is usually a nitrogen limiting environment. Ammonia, produced from deaminization of amino acid (Berg et al., 2002), could work as the interspecific signal, as well as additional source of nitrogen for the fungus L. procerum. In this process, the fungus would avoid the risk of nitrogen shortage in this symbiotic system. Also, the nitrogen content in artificial bacterial broth used in this study is similar to that of pine phloem according to previous reports (Ayres et al., 2000,Wang, 2011) and technical information on bacterial broth (Supplementary Table S3), which makes the concentration used in this study a reasonable reflection of nitrogen content found in actual field conditions.

This is the first study to identify specific bacterial volatiles that influence mutualism within the framework of multi-species interactions in the bark beetle-microbe symbiosis. Much research has been conducted to reveal functions of bacterial volatiles in this symbiosis. For example, the combination of bacterial volatiles and pine phloem chemistry regulate fungal reproduction and growth (Adams et al., 2009). In addition, bacterial volatiles alter the carbon allocation within the symbiosis formed by RTB and its fungal associates (Zhou et al., 2016). However, none examined the chemical composition of bacterial volatiles nor investigated the active component. In this study, 67 volatiles were detected in total, and multivariate statistical analysis showed a significant correlation between carbon utilization patterns, and thus only seven volatiles were selected for chemical identification.

As the most abundant microbial associate in this symbiosis, associated bacteria have been reported to provide protection for bark beetles against antagonistic fungi (Scott et al., 2008). In the RTB-microbe symbiosis, the three dominant bacterial species cohabitating on the larval surface, larval guts and frass of both RTB larvae and adults (Morales-Jiménez et al., 2009; Xu et al., 2015, 2016b; Zhou et al., 2016) forms a symbiotic relationship with $L$. procerum (Cheng et al., 2016). In pine phloem, carbon sources available for both fungal and bacterial symbionts are mainly D-pinitol and D-glucose (Cheng et al., 2016). Thus, bacteria, fungi and their insect host RTB may face the problem of resource allocation in the face of resource limitation. Although these two carbohydrates can be assimilated by bacteria and L. procerum, bacteria and the fungus grow faster when using D-glucose rather than D-pinitol, whereas D-pinitol demonstrated antagonistic effects on insects including RTB (Reese et al., 1982; Chaubal et al., 2005; Zhou et al., 2016). Therefore, the altered consumption sequence results in the suppressed consumption of the best carbon source D-glucose by L. procerum, and this carbohydrate would be consumed by both bacteria and RTB. The interaction between associated bacteria and the fungus may be a consequence of long term coevolution.

An increasing body of research has revealed essential roles of microbe-microbe interactions in the maintenance of insect-microbe symbiosis. For instance, the genus Pseudonocardia inhibits colonization of one antagonistic fungus Escovopsis by producing antibiotics in the ant-fungus symbiosis (Currie et al., 1999). However, few of those studies conduct analyses to unmask the biochemical mechanisms mediating the microbial symbiont interaction. This work expands our understanding of the insect-microbe symbiosis. In addition, manipulation of these biochemicals in further studies would provide novel pathways for pest management.

\section{Conflict of Interest}

The authors declare no conflict of interest.

\section{Acknowledgements}

We appreciate the constructive comments from two anonymous reviewers. This project was funded by the National Key Research and Development Program (2016YFC1200600) and CAS Strategic R\&D Program (XDB11050000 and QYZDJ-SSW-SMC024).

\section{References}

Adams AS, Currie CR, Cardoza Y, Klepzig KD, Raffa KF. (2009). Effects of symbiotic bacteria and tree chemistry on the growth and reproduction of bark beetle fungal symbionts. Can J For Res 39: 1133-1147.

Adams AS, Aylward FO, Adams SM, Erbilgin N, Aukema BH, Currie CR et al. (2013). Mountain pine beetles colonizing historical and naïve host trees are associated with a bacterial community highly enriched in genes contributing to terpene metabolism. Appl Environ Microbiol 79: 3468-3475.

Audrain B, Farag MA, Ryu C-M, Ghigo J-M. (2015). Role of bacterial volatile compounds in bacterial biology. FEMS Microbiol Rev 39: 222-233.

Ayres MP, Wilkens RT, Ruel JJ, Lombardero MJ, Vallery E. (2000). Nitrogen budgets of phloem-feeding bark 
beetles with and without symbiotic fungi. Ecology 81: 2198-2210.

Behrends V, Tredwell GD, Bundy JG. (2011). A software complement to AMDIS for processing GC-MS metabolomic data. Anal Biochem 415: 206-208.

Berg JM, Tymoczko JL, Stryer L. (2002). Biochemistry, 5th edn.W. H. Freeman: New York.

Bernier SP, Létoffé S, Delepierre M, Ghigo J-M. (2011). Biogenic ammonia modifies antibiotic resistance at a distance in physically separated bacteria. Mol Microbiol 81: 705-716.

Bladen HA, Bryant MP, Doetsch RN. (1961). A study of bacterial species from the rumen which produce ammonia from protein hydrolyzate. Appl Microbiol 9: 175-180.

Boone CK, Keefover-Ring K, Mapes AC, Adams AS, Bohlmann J, Raffa KF. (2013). Bacteria associated with a tree-killing insect reduce concentrations of plant defense compounds. J Chem Ecol 39: 1003-1006.

Brand J, Bracke J, Britton L, Markovetz A, Barras S. (1976). Bark beetle pheromones: production of verbenone by a mycangial fungus of Dendroctonus frontalis. J Chem Ecol 2: 195-199.

Bronstein JL, Wilson WG, Morris WF. (2003). Ecological dynamics of mutualist/antagonist communities. Am Nat 162: S24-S39.

Chaubal R, Pawar PV, Hebbalkar GD, Tungikar VB, Puranik VG, Deshpande VH et al. (2005). Larvicidal activity of Acacia nilotica extracts and isolation of D-pinitol - a bioactive carbohydrate. Chem Biodivers 2: 684-688

Cheng C, Xu L, Xu D, Lou Q, Lu M, Sun J. (2016). Does cryptic microbiota mitigate pine resistance to an invasive beetle-fungus complex? Implications for invasion potential. Sci Rep 6: 33110 .

Cheng C, Zhou F, Lu M, Sun J. (2015). Inducible pine rosin defense mediates interactions between an invasive insect-fungal complex and newly acquired sympatric fungal associates. Integr Zool 10: 453-464.

Currie CR, Scott JA, Summerbell RC, Malloch D. (1999). Fungus-growing ants use antibiotic-producing bacteria to control garden parasites. Nature 398: 701-704.

Douglas AE. (2015). Multiorganismal insects: diversity and function of resident microorganisms. Annu Rev Entomol 60: 17-34.

Eno CF, Blue WG, Good JM. (1955). The effect of anhydrous ammonia on nematodes, fungi, bacteria, and nitrification in some florida soils. Soil Sci Soc Am J 19: 55-58.

Georgelin E, Loeuille N. (2014). Dynamics of coupled mutualistic and antagonistic interactions, and their implications for ecosystem management. $J$ Theor Biol 346: $67-74$.

Harrington TC. (2005). Ecology and evolution of mycophagous bark beetles and their fungal partners. In: Vega FE, Blackwell M (eds). Insect-Fungal Associations: Ecology and Evolution. Oxford University Press: Oxford, pp 257-291.

Herre EA, Knowlton N, Mueller UG, Rehner SA. (1999). The evolution of mutualisms: exploring the paths between conflict and cooperation. Trends Ecol Evol 14: $49-53$.

Hofstetter R, Cronin J, Klepzig K, Moser J, Ayres M. (2006). Antagonisms, mutualisms and commensalisms affect outbreak dynamics of the southern pine beetle. Oecologia 147: 679-691.

Howell C, Beier R, Stipanovic R. (1988). Production of ammonia by Enterobacter cloacae and its possible role in the biological control of Pythium preemergence damping-off by the bacterium. Phytopathology 78: 1075-1078.

Jesús M-J, Vera-Ponce de Leon A, Garcia-Dominguez A, Martinez-Romero E, Zuniga G, Hernandez-Rodriguez C. (2013). Nitrogen-fixing and uricolytic bacteria associated with the gut of Dendroctonus rhizophagus and Dendroctonus valens (Curculionidae: Scolytinae). Microb Ecol 66: 200-210.

Kai M, Haustein M, Molina F, Petri A, Scholz B, Piechulla B. (2009). Bacterial volatiles and their action potential. Appl Microbiol Biotechnol 81: 1001-1012.

Klepzig K, Moser J, Lombardero M, Ayres M, Hofstetter R, Walkinshaw C. (2001). 13 Mutualism and antagonism: ecological interactions among bark beetles, mites and fungi. In: Jeger MJ, Spence NJ (eds). Biotic Interactions in Plant-Pathogen Associations. CABI Publishing: Wallingford, pp 237-267.

Lee S, Kim J-J, Breuil C. (2006). Pathogenicity of Leptographium longiclavatum associated with Dendroctonus ponderosae to Pinus contorta. Can J For Res 36: 2864-2872.

Lemfack MC, Nickel J, Dunkel M, Preissner R, Piechulla B. (2014). mVOC: a database of microbial volatiles. Nucleic Acids Res 42: D744-D748.

Li D, Shi J, Luo Y. (2015). Mutualism between the Eurasian woodwasp, Sirex noctilio (Hymenoptera:Siricidae) and its fungal symbiont Amylostereum areolatum (Russulales:Amylostereaceae). Acta Entomol Sin 58: 1019-1029.

Lou Q, Lu M, Sun J. (2014). Yeast diversity associated with invasive Dendroctonus valens killing Pinus tabuliformis in China using culturing and molecular methods. Microb Ecol 68: 397-415.

Lu M, Zhou XD, De Beer ZW, Wingfield MJ, Sun J. (2009). Ophiostomatoid fungi associated with the invasive pine-infesting bark beetle, Dendroctonus valens, in China. Fungal Divers 38: 133-145.

Lu M, Wingfield MJ, Gillette N, Sun J. (2011). Do novel genotypes drive the success of an invasive bark beetlefungus complex? Implications for potential reinvasion. Ecology 92: 2013-2019.

Lu M, Hulcr J, Sun J. (2016). The role of symbiotic microbes in insect invasions. Annu Rev Ecol Evol S 47: 487-505.

Moir JW. (2011). Nitrogen Cycling in Bacteria: Molecular Analysis. Caister Academic Press: York, UK.

Morales-Jiménez J, Zúñiga G, Villa-Tanaca L, HernándezRodríguez C. (2009). Bacterial community and nitrogen fixation in the red turpentine beetle, Dendroctonus valens LeConte (Coleoptera: Curculionidae: Scolytinae). Microb Ecol 58: 879-891.

Novak M, Lah L, Šala M, Stojan J, Bohlmann J, Komel R. (2015). Oleic acid metabolism via a conserved cytochrome p450 system-mediated $\omega$-hydroxylation in the bark beetle-associated fungus Grosmannia clavigera. PLoS One 10: e0120119.

Reese J, Chan B, Waiss A JR. (1982). Effects of cotton condensed tannin, maysin (Corn) and pinitol (soybeans) on Heliothis zea growth and development. J Chem Ecol 8: 1429-1436.

Robacker D, Lauzon C, He X. (2004). Volatiles production and attractiveness to the Mexican fruit fly of Enterobacter agglomerans isolated from apple maggot and Mexican fruit flies. J Chem Ecol 30: 1329-1347.

Ryu C-M, Farag MA, Hu C-H, Reddy MS, Wei H-X, Paré PW et al. (2003). Bacterial volatiles promote growth in Arabidopsis. Proc Natl Acad Sci USA 100: 4927-4932. 
Sagara N. (1975). Ammonia Fungi: A Chemoecological Grouping of Terrestrial Fungi. Contributions from the Biological Laboratory. Kyoto University: Tokyo.

Schippers B, Meijer JW, Liem JI. (1982). Effect of ammonia and other soil volatiles on germination and growth of soil fungi. Fungal Biol 79: 253-259.

Scott JJ, Oh D-C, Yuceer MC, Klepzig KD, Clardy J, Currie CR. (2008). Bacterial protection of beetlefungus mutualism. Science 322: 63-63.

Sun J, Lu M, Gillette NE, Wingfield MJ. (2013). Red turpentine beetle: innocuous native becomes invasive tree killer in China. Annu Rev Entomol 58: 293-311.

Therrien J, Mason C, Cale J, Adams A, Aukema B, Currie C et al. (2015). Bacteria influence mountain pine beetle brood development through interactions with symbiotic and antagonistic fungi: implications for climatedriven host range expansion. Oecologia 179: 1-19.

van Steenbergern TJM, van der Mispel LMS, de Graaff J. (1986). Effects of ammonia and volatile fatty acids produced by oral bacteria on tissue culture cells. J Dent Res 65: 909-912.

Wang B. (2011). Interactions Between an Invasive Bark Beetle, Dendroctonus Valens (Coleoptera: Scolytidae), and its Associated Fungi, Institute of Zoology. Chinese Academy of Sciences: Beijing.

Wang B, Salcedo C, Lu M, Sun J. (2012). Mutual interactions between an invasive bark beetle and its associated fungi. Bull Entomol Res 102: 71-77.

Wang B, Lu M, Cheng C, Salcedo C, Sun J. (2013). Saccharide-mediated antagonistic effects of bark beetle fungal associates on larvae. Biol Lett 9: 20120787.

Wang L, Feng Y, Tian J, Xiang M, Sun J, Ding J et al. (2015). Farming of a defensive fungal mutualist by an attelabid weevil. ISME J 9: 1793-1801.
Wang X, Li GH, Zou CG, Ji XL, Liu T, Zhao PJ et al. (2014). Bacteria can mobilize nematode-trapping fungi to kill nematodes. Nat Commun 5: 5776.

Xu L, Lou Q, Cheng C, Lu M, Sun J. (2015). Gut associated bacteria of Dendroctonus valens and their role in verbenone pheromone production. Microb Ecol 70: 1012-1023.

Xu L, Lu M, Sun J. (2016a). Invasive bark beetle-associated microbes degrade a host defensive monoterpene. Insect Sci 23: 183-190.

Xu L, Lu M, Xu D, Chen L, Sun J. (2016b). Sexual variation of bacterial microbiota of Dendroctonus valens guts and frass in relation to verbenone production. J Insect Physiol 95: 110-117.

Zhou F, Lou Q, Wang B, Xu L, Cheng C, Lu M et al. (2016). Altered carbohydrates allocation by associated bacteria-fungi interactions in a bark beetle-microbe symbiosis. Sci Rep 6: 20135.

(c) (1) (2) This work is licensed under a Creative (c) ${ }_{\text {BV }}$ NC sA Commons Attribution-NonCommercialShareAlike 4.0 International License. The images or other third party material in this article are included in the article's Creative Commons license, unless indicated otherwise in the credit line; if the material is not included under the Creative Commons license, users will need to obtain permission from the license holder to reproduce the material. To view a copy of this license, visit http://creativecommons.org/ licenses/by-nc-sa/4.0/

(c) The Author(s) 2017

Supplementary Information accompanies this paper on The ISME Journal website (http://www.nature.com/ismej) 